\title{
CONSERVAÇÃO DE PERAS MINIMAMENTE PROCESSADAS SUBMETIDAS A TRATAMENTOS QUÍMICOS ${ }^{1}$
}

\author{
ANA CAROLINA VILAS BOAS², PAÔLA DE CASTRO HENRIQUE 3 , \\ LUIZ CARLOS DE OLIVEIRA LIMA ${ }^{4}$, MICHEL CARDOSO DE ANGELIS PEREIRA ${ }^{5}$
}

RESUMO- O trabalho teve como objetivo testar a eficácia de tratamentos químicos na manutenção da qualidade de peras 'Williams' minimamente processadas. Inicialmente, realizaram-se a lavagem, a sanitização e a retirada das sementes dos frutos. Em seguida, foram realizados cortes no formato de palitos, e os mesmos foram imersos nas soluções, compondo os tratamentos: ácido ascórbico a $2 \%$ (controle); ácido ascórbico a $2 \%$ + cloreto de cálcio a $2 \%$; ácido ascórbico a $2 \%$ + ácido cítrico a $2 \%$; ácido cítrico a $1 \%$; cloridrato de L-cisteína a 1\%. Os frutos foram acondicionados em bandejas de polipropileno, armazenados em câmara fria a $5^{\circ} \mathrm{C}$ por 12 dias e avaliados a cada três dias. O tratamento com cloridrato de L-cisteína a $1 \%$ foi o mais eficaz na inibição do escurecimento em peras minimamente processadas; no entanto, frutos tratados com ácido ascórbico + cloreto de cálcio apresentaram maior firmeza durante todo o período avaliado, além de quantidades significativamente maiores de vitamina $\mathrm{C}$ quando comparado a formulações que não continham ácido ascórbico na composição.

Termos para indexação: Pyrus communis L., coloração, firmeza, vitamina C, qualidade.

\section{CONSERVATION OF MINIMALLY PROCESSED PEARS SUBJECTED TO CHEMICAL TREATMENTS}

\begin{abstract}
The study aimed to test the effectiveness of chemical additives in maintaining the quality of 'Williams' minimally processed pears. At first, the washing, the sanitization and the removal of seeds from the fruits were performed. Then, they were cut in sticks and then immersed in the solutions, comprising the following treatments: ascorbic acid $2 \%$ (control), ascorbic acid $2 \%+$ calcium chloride $2 \%$, ascorbic acid $2 \%$ + citric acid $2 \%$, citric acid 1\%, L-cysteine hydrochloride $1 \%$. Fruits were packed in polypropylene trays, in cold storage at $5{ }^{\circ} \mathrm{C}$ for 12 days and every three days they were evaluated. The treatment of L-cysteine hydrochloride $1 \%$ was the most effective in inhibiting browning in minimally processed pears, however, fruits treated with ascorbic acid + calcium chloride showed higher firmness during the study period and significantly higher levels of vitamin $\mathrm{C}$ when compared to formulations that did not contain ascorbic acid in the composition.
\end{abstract}

Index terms: Pyrus communis L., color, firmness, vitamin C, quality.

${ }^{1}$ (Trabalho 247-14). Recebido em: 03-09-2014. Aceito para publicacão em: 05-01-2015.

${ }^{2}$ Doutoranda em Ciência dos Alimentos, Universidade Federal de Lavras. Bolsista CNPq . E-mail: vbanacarolina@yahoo.com.br

${ }^{3}$ Doutoranda em Ciência dos Alimentos, Universidade Federal de Lavras. Bolsista FAPEMIG. E-mail: paolahenrique@yahoo.com.br

${ }^{4}$ Doutor, Docente do Departamento de Ciência dos Alimentos, Universidade Federal de Lavras. E-mail: 1colima@dca.ufla.br

${ }^{5}$ Doutor, Docente do Departamento de Ciência dos Alimentos, Universidade Federal de Lavras. E-mail: deangelis@hotmail.com 


\section{INTRODUÇÃO}

Frutas minimamente processadas são caracterizadas por uma curta vida útil devido a sua rápida deterioração. Esses produtos geralmente são colhidos, lavados, higienizados, descascados, cortados, tratados (quando necessário) e adequadamente embalados de forma a oferecer conveniência e segurança ao consumidor, além da qualidade nutricional, que tem sido cada vez mais exigida por uma população bem informada quanto aos benefícios dos alimentos à saúde.

Peras minimamente processadas apresentam alta sensibilidade ao escurecimento após o processamento. Por esta razão, vários estudos têm sido desenvolvidos com o objetivo de prolongar a vida útil de peras minimamente processadas (BOTREL et al., 2010; PEREZ-CABRERA et al., 2011; XIAO et al., 2011; GOMES et al., 2012). Um dos grandes problemas que afetam a qualidade desse produto é o escurecimento enzimático, causado principalmente pela polifenoloxidase, e, dessa forma, o uso de agentes inibidores do escurecimento é indispensável.

Os tratamentos de superfície, onde pedaços de frutas são imersos em soluções aquosas contendo agentes antimicrobianos, antioxidantes, sais de cálcio ou ingredientes funcionais, tais como sais minerais e vitaminas, são amplamente aplicados para melhorar a qualidade de frutas processadas (OMS-OLIU et al., 2010). Entre as formulações encontradas para controlar o escurecimento em produtos minimamente processados, estão o ácido ascórbico, o ácido cítrico, o cloreto de cálcio e o cisteína (CHIABRANDO; GIACALONE, 2011; GHIDELLI et al., 2013).

Sendo assim, o objetivo do trabalho foi testar a eficácia de tratamentos químicos na inibição do escurecimento e na manutenção da qualidade de peras 'Williams' minimamente processadas.

\section{MATERIAL E MÉTODOS}

As peras 'Williams' utilizadas no experimento foram adquiridas no comércio local de Lavras-MG. O experimento foi conduzido no Laboratório de PósColheita de Frutas e Hortaliças, no Departamento de Ciência dos Alimentos da Universidade Federal de Lavras.

Os frutos foram selecionados quanto à ausência de injúrias, podridão e aroma característicos de deterioração, lavados com detergente neutro e sanitizados com hipoclorito de sódio $100 \mathrm{mg} \mathrm{L}^{-1}$ por 10 minutos para a desinfecção superficial.

A parte central dos frutos foi retirada, e cortes longitudinais foram realizados no formato de palitos (4,2 cm x 1,3 cm x 1,3 cm), com o auxílio de um processador de frutas. Os pedaços obtidos foram imersos por 3 minutos nas soluções compondo os tratamentos: ácido ascórbico a 2\% (controle); ácido ascórbico a $2 \%$ + cloreto de cálcio a $2 \%$; ácido cítrico a $1 \%$; ácido ascórbico a $2 \%+$ ácido cítrico a $2 \%$ e cloridrato de L-cisteína a $1 \%$. Então, os pedaços passaram por um processo de drenagem para a retirada do excesso de líquido e foram em seguida acondicionados em bandejas rígidas de polipropileno (13 cm x $10 \mathrm{~cm}$ x $6 \mathrm{~cm}$ ) com tampa própria, e estas foram mantidas em câmara fria, na temperatura de aproximadamente $5^{\circ} \pm 1^{\circ} \mathrm{C}$ e umidade relativa de aproximadamente $90 \%$, por doze dias. Cada embalagem continha cerca de $100 \mathrm{~g}$ de produto.

Durante o período de armazenamento, análises foram realizadas a cada três dias. O teor de sólidos solúveis foi mensurado, utilizando refratômetro digital ATAGO PR-100, com compensação automática de temperatura a $20^{\circ} \mathrm{C}$, previamente calibrado com água destilada. Os resultados foram expressos em \% (AOAC, 2007).

Acidez titulável foi determinada por metodologia sugerida pela AOAC (2007), realizandose titulação com solução de hidróxido de sódio $(\mathrm{NaOH})$ 0,1 mol L-1, sendo os resultados expressos em porcentagem (\%) de ácido málico.

Os açúcares solúveis totais foram quantificados pelo método de Antrona (DISCHE, 1962). Foi realizada a leitura das absorbâncias das amostras a $620 \mathrm{~nm}$, em espectrofotômetro Beckman 640 B com sistema computadorizado. Os resultados foram expressos em mg de açúcares totais em 100 $\mathrm{g}^{-1}$ de fruto.

A mensuração do $\mathrm{pH}$ foi feita empregando-se um pHmetro Tecnal (Tec 3M) com eletrodo de vidro, conforme recomendações da AOAC (2007).

A quantificação dos teores de vitamina $\mathrm{C}$ (ácido ascórbico) foi feita por método colorimétrico, empregando-se 2,4 dinitrofenil-hidrazina, segundo Strohecker e Henning (1967). A leitura foi realizada a $520 \mathrm{~nm}$ em espectrofotômetro Beckman 640B, com sistema computadorizado, e os resultados foram expressos em mg de ácido ascórbico em 100 $\mathrm{g}^{-1}$ de fruto. Para avaliar a coloração dos frutos, foi empregado o colorímetro Minolta, modelo CR 400, no sistema da Commission Internacionale de Eclairage (CIE, 1978), pesquisando-se as coordenadas L*, a* e b*.

A firmeza das amostras foi medida por um penetrômetro (Medidor de dureza de frutos), visando a verificar a força de compressão. A probe ou ponteira utilizada foi de $8 \mathrm{~mm}$, e os resultados foram expressos 
em Newtons (N).

As pectinas totais e solúveis foram extraídas segundo a técnica descrita por McCready e McComb (1952) e determinadas colorimetricamente, segundo Bitter e Muir (1962). Os resultados foram expressos em mg de ácido galacturônico por $100 \mathrm{~g}$ de polpa.

O delineamento experimental utilizado foi o inteiramente casualizado (DIC), em esquema fatorial $(5 \times 5)$, composto por cinco tratamentos químicos e cinco períodos de armazenamento $(0 ; 3$; 6; 9 e 12 dias), com 3 repetições. O teste de Tukey, a 5\% de probabilidade, foi utilizado para comparar os tratamentos dentro de cada tempo. Os modelos de regressão polinomiais, utilizados para tempo de armazenamento, foram selecionados com base na significância do teste $\mathrm{F}$ de cada modelo testado e pelo coeficiente de determinação.

\section{RESULTADOS E DISCUSSÃO}

A variável $L^{*}$ é um eficiente indicador do escurecimento de frutos durante o armazenamento, quer resultante de reações oxidativas de escurecimento, quer do aumento da concentração de pigmentos (ROCHA; MORAIS, 2003). Sabe-se que o valor de $\mathrm{L}^{*}$ tende a diminuir com o aumento do período de armazenamento. Sendo assim, o efeito dos diferentes aditivos nos valores de $\mathrm{L}^{*}, \mathrm{a}^{*} \mathrm{e} \mathrm{b}^{*}$ em peras minimamente processadas é apresentado na Figura 1. Quando se comparam o primeiro e o último dia de armazenamento, observa-se que o valor de $\mathrm{L}^{*}$ decresceu ao longo do tempo de armazenamento para todos os tratamentos testados, sendo ácido ascórbico + ácido cítrico o menos eficaz em conter o escurecimento das fatias em relação aos demais, apresentando valores médios de 28,25 no último período avaliado. O maior valor de $\mathrm{L}^{*}$ foi encontrado para as peras tratadas com cloridrato de L-cisteína, sendo este o melhor tratamento para inibir o escurecimento das peras, juntamente com o tratamento de ácido ascórbico a $2 \%$, que não se diferenciou estatisticamente do anterior nos períodos finais de armazenamento. Os resultados encontrados estão de acordo com Melo et al. (2009), que, trabalhando com banana 'Maçã' minimamente processada, observaram que o tratamento com cisteína foi o mais eficaz no controle do escurecimento. Da mesma forma, Botrel et al. (2010), trabalhando com revestimento ativo de amido na conservação de peras minimamente processadas, também observaram a eficiência da cisteína na inibição do escurecimento dos frutos.

Os valores de $a^{*}$ (que variam do verde ao vermelho) mostraram menores valores para os frutos tratados com cloridrato de L-cisteína, indicando que os mesmos se encontravam mais verdes, fato evidente especialmente aos 12 dias de armazenamento. A variável $b^{*}$ foi influenciada pelos tratamentos, bem como pelo tempo de armazenamento, sendo que as peras tratadas com ácido ascórbico apresentaram maiores valores, indicando que se encontravam mais amarelas que as demais.

A Figura 2 mostra os valores de $\mathrm{pH}$ e acidez titulável dos frutos armazenados a $5^{\circ} \mathrm{C}$ por 12 dias. O tratamento com ácido ascórbico + cloreto de cálcio apresentou menores valores de $\mathrm{pH}$, atingindo 3,62 aos 12 dias de armazenamento, não se diferenciando do tratamento com ácido cítrico, no mesmo tempo. Botrel et al. (2010), trabalhando com peras minimamente processadas, observaram menores valores de $\mathrm{pH}$ nos frutos que continham lactato de cálcio na composição do revestimento, sugerindo uma influência do cálcio na respiração dos frutos, contribuindo assim para controlar desordens fisiológicas e retardar o processo de senescência, visto que proporciona maior resistência na parede celular, além de o aumento de $\mathrm{pH}$ estar relacionado com a senescência dos frutos.

Sabe-se que a acidez em produtos hortícolas é atribuída, principalmente, aos ácidos orgânicos que se encontram dissolvidos nos vacúolos das células, tanto na forma livre, como na combinada, como sais, ésteres, glicosídeos, etc. Em alguns produtos, os ácidos orgânicos não só contribuem para a acidez, como também para o aroma característico, porque alguns componentes são voláteis (CHITARRA; CHITARRA, 2005). Os valores de acidez titulável (Figura 2) mostraram maior \% de ácido málico nos frutos tratados com cloridrato de L-cisteína, apresentando $0,33 \%$ no último período de armazenamento.

A Figura 3 apresenta o teor de sólidos solúveis e de açúcares solúveis totais em peras minimamente processadas. Todos os aditivos mostraram uma tendência à queda nos valores de sólidos solúveis, indicando provável consumo desses compostos pelo processo respiratório durante o armazenamento. Já com relação ao teor de açúcares solúveis totais, os maiores valores foram referentes aos frutos tratados com ácido ascórbico a 2\%. Um decréscimo acentuado nos valores de açúcares ao longo do tempo foi observado no tratamento com ácido cítrico (Figura 3 ), provavelmente pelo aumento da taxa respiratória desses frutos.

A Figura 4 apresenta o teor de vitamina $\mathrm{C}$ e a firmeza dos frutos tratados e armazenados por 12 dias. Todos os tratamentos que apresentavam ácido ascórbico em sua composição mostraram maiores 
valores de vitamina $\mathrm{C}$, como o esperado. Dessa forma, frutos tratados com ácido ascórbico, ácido ascórbico + cloreto de cálcio e ácido ascórbico + ácido cítrico apresentaram valores médios de 164,20; 139,15 e $155,27 \mathrm{mg} \mathrm{em} 100 \mathrm{~g}^{-1}$, respectivamente. Resultados semelhantes foram encontrados por Carvalho e Lima (2002) em kiwis, em que o tratamento com ácido ascórbico forneceu teor de vitamina C de $25 \%$ a mais que os tratamentos com ácido cítrico e cloreto de cálcio, mostrando que o ácido ascórbico foi bem absorvido pelos tecidos dos frutos.

Com relação à firmeza, as peras tratadas com ácido ascórbico + cloreto de cálcio apresentaram os maiores valores ao longo de todo o armazenamento, retardando o amaciamento dos frutos. Esses resultados estão de acordo com Machado et al. (2008), que também observaram o benefício da aplicação do cloreto de cálcio na manutenção da firmeza em melões Cantaloupe armazenados por 18 dias. Outra influência positiva da aplicação de cloreto de cálcio foi constatada por Silva et al. (2003), que verificaram que fatias de abacaxi tratadas com $1 \%$ de cloreto de cálcio apresentaram uma textura mais elevada ao final do experimento, o que representou maior firmeza em comparação com os demais tratamentos realizados. Usualmente, modificações no grau de contato entre as células ocorrem devido à degradação e à solubilização das pectinas e a modificações na estrutura das paredes, decorrentes da ação de enzimas, como a poligalacturonase e a pectinametilesterase. Dessa forma, com a evolução da maturação e do armazenamento, há decomposição das macromoléculas como protopectinas, celulose, hemicelulose e amido, amaciando as paredes celulares pela diminuição da força coesiva que mantém as células unidas (CHITARRA; CHITARRA, 2005). Assim, a adição de cloreto de cálcio leva à formação de pectato de cálcio, que mantém a parede celular mais firme pela insolubilização do material péctico.

A Figura 5 apresenta o teor de pectina total e solúvel dos frutos submetidos aos diferentes aditivos químicos ao longo do armazenamento. Com relação ao teor de pectina total, os maiores valores médios foram encontrados para ácido ascórbico + cloreto de cálcio, o que confirma a maior firmeza desses frutos. Já com relação ao teor de pectina solúvel, menores valores foram encontrados para ácido ascórbico + cloreto de cálcio. Esses resultados estão de acordo com Xisto et al. (2004), que também observaram menores valores de pectina solúvel em goiabas tratadas com cloreto de cálcio, apresentando, assim, maior firmeza. Já os maiores valores foram encontrados para frutos tratados com cloridrato de L-cisteína, mostrando que, embora seja o mais eficaz para conter o escurecimento dos frutos, não foi capaz de manter sua firmeza ao longo do período avaliado. 

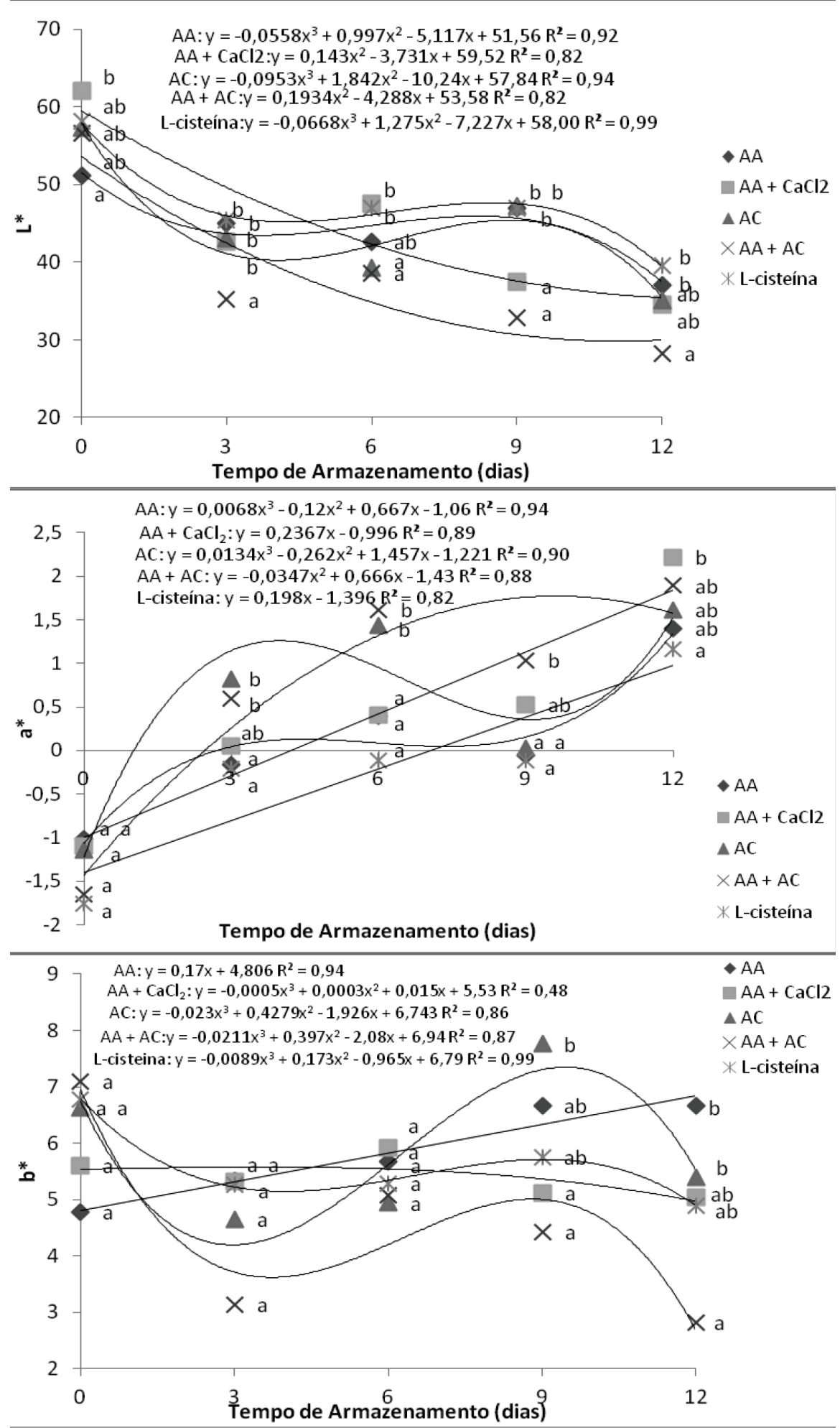

FIGURA 1 - Valores de L*, a* e b* de peras minimamente processadas submetidas a diferentes aditivos químicos. 


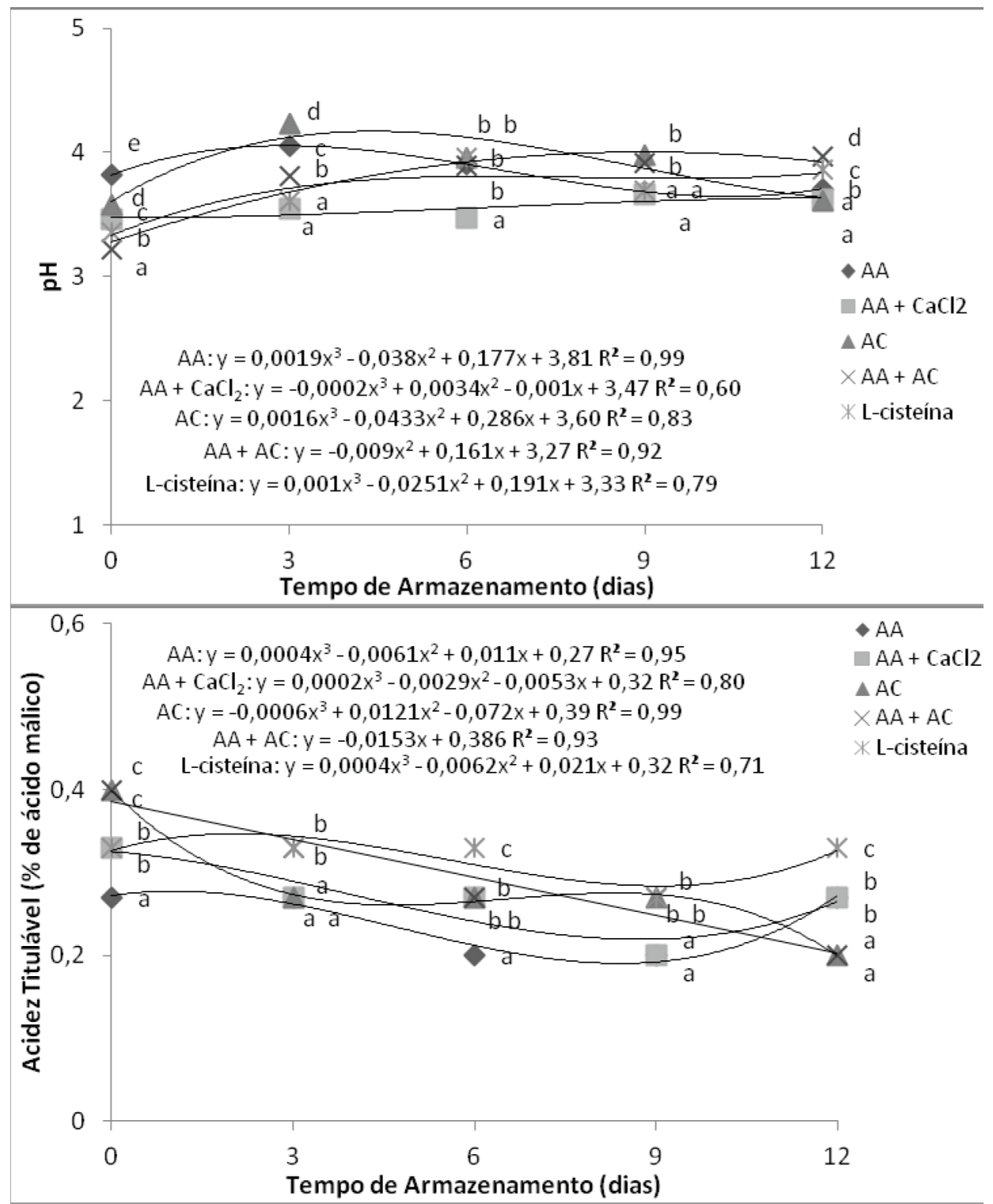

FIGURA 2 - pH e teor de acidez titulável de peras minimamente processadas submetidas a diferentes aditivos químicos. 

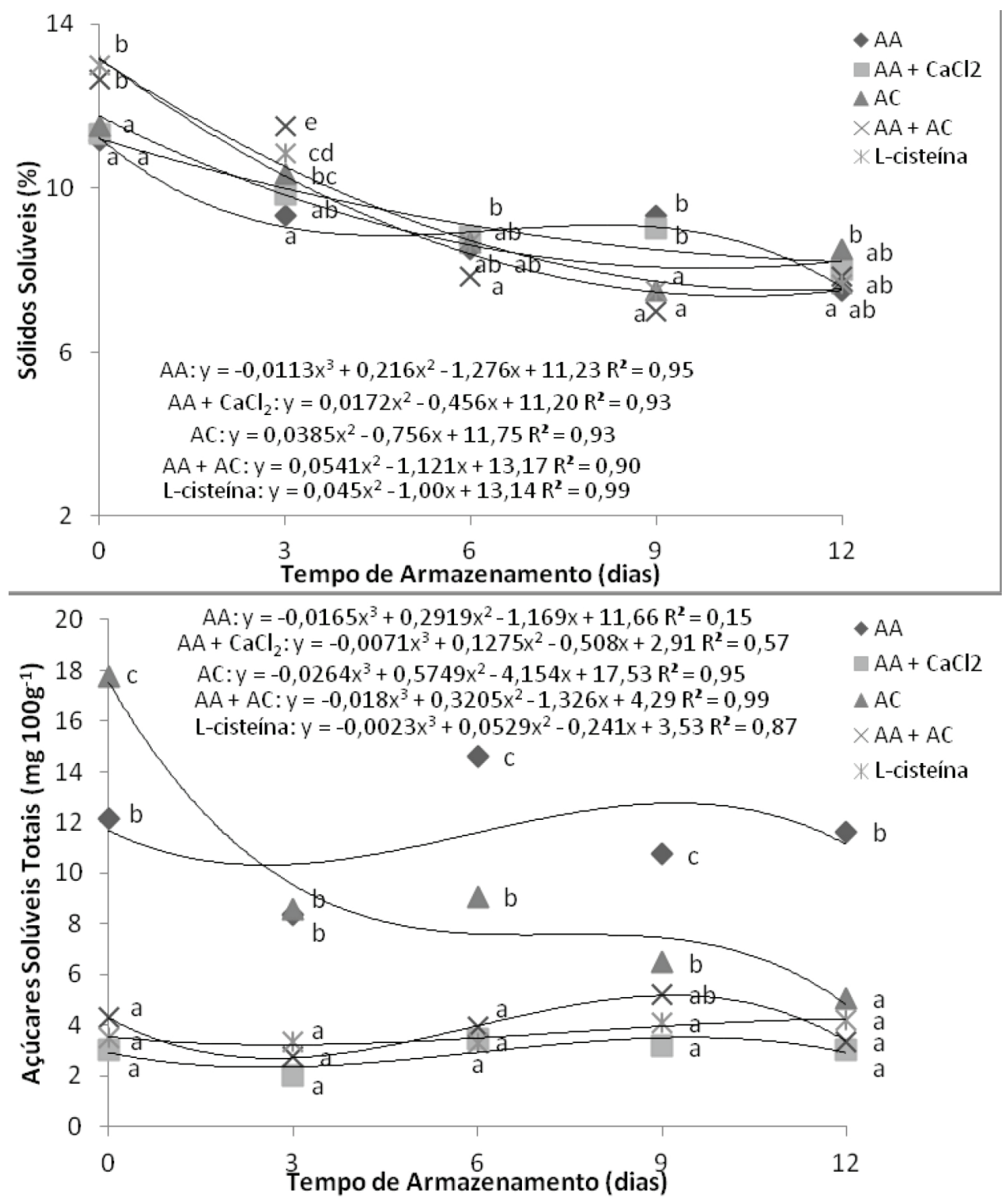

FIGURA 3 - Teor de sólidos solúveis e açúcares solúveis totais de peras minimamente processadas submetidas a diferentes aditivos químicos. 

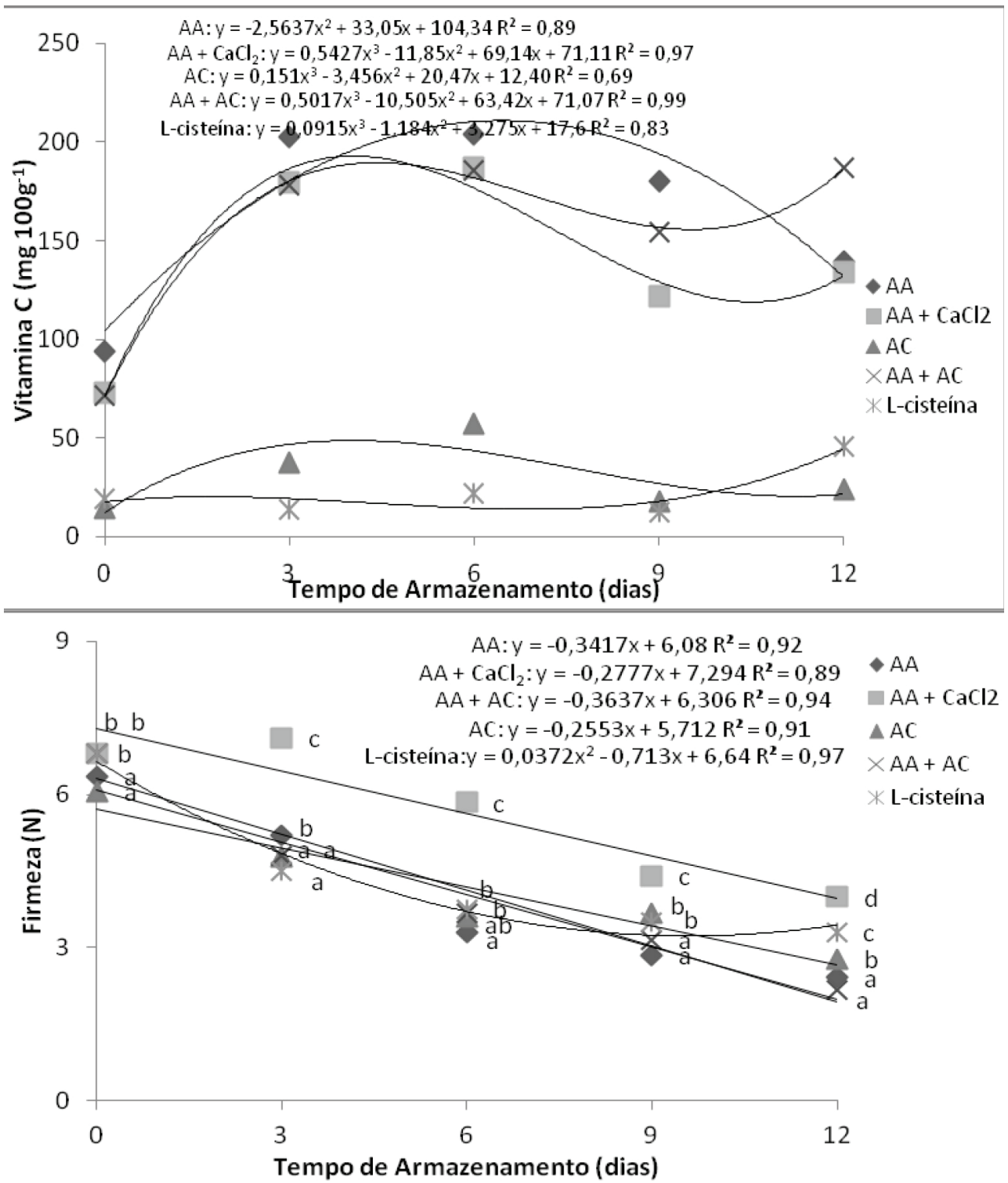

FIGURA 4 - Teor de vitamina $C$ e firmeza de peras minimamente processadas submetidas a diferentes aditivos químicos. 

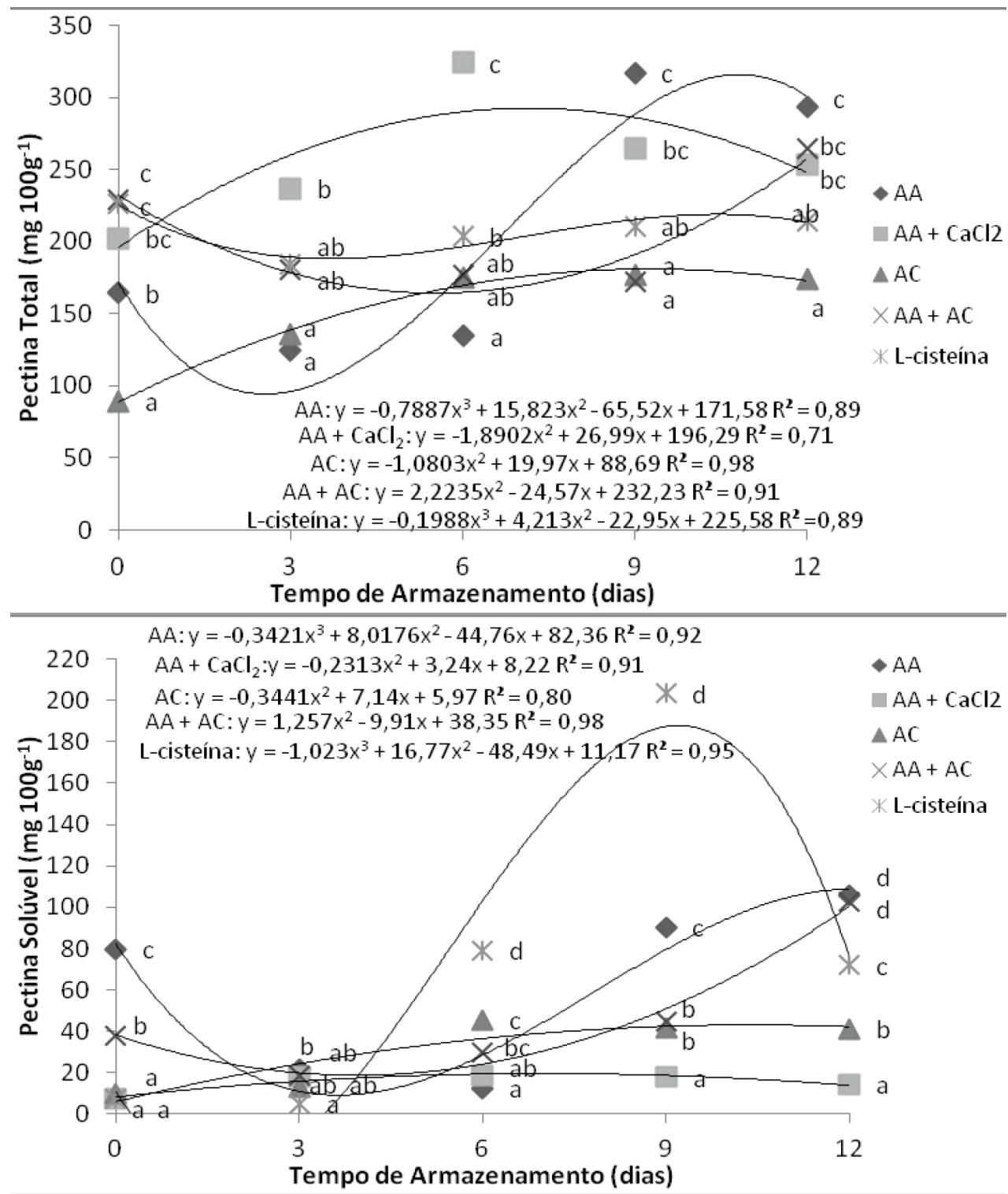

FIGURA 5 - Teor de pectina total e pectina solúvel em peras minimamente processadas submetidas a diferentes aditivos químicos. 


\section{CONCLUSÃO}

O tratamento com cloridrato de L-cisteína a $1 \%$ foi o mais eficaz na inibição do escurecimento em peras minimamente processadas, armazenadas por 12 dias a $5^{\circ} \mathrm{C}$, porém frutos tratados com ácido ascórbico + cloreto de cálcio apresentaram maior firmeza durante todo o período avaliado, menor $\mathrm{pH}$, além de quantidades significativamente maiores de vitamina $\mathrm{C}$ quando comparado a formulações que não continham ácido ascórbico na composição.

\section{AGRADECIMENTOS}

Os autores agradecem ao CNPq e à FAPEMIG, pelo apoio à pesquisa.

\section{REFERÊNCIAS}

AOAC - Association of Official Analytical Chemists. Official methods of the Association of the Agricultural Chemists. 18 ${ }^{\text {th }}$ ed. Washington, 2007.

BITTER, T.; MUIR, H.M. A modified uronic acid carbazole reaction. Analytical Biochemistry, New York, v. 4, n. 4, p. 330-334, 1962.

BOTREL, D.A.; SOARES, N.F.F.; CAMILLOTO, G.P.; FERNANDES, R.V.B. Revestimento ativo de amido na conservação pós-colheita de pera Williams minimamente processada. Ciência Rural, Santa Maria, v. 40, n.8, p. 1814-1820, 2010.

CARVALHO, A.V.; LIMA, L.C.O. Qualidade de kiwis minimamente processados e submetidos a tratamento com ácido ascórbico, ácido cítrico e cloreto de cálcio. Pesquisa Agropecuária Brasileira, Brasília, v. 37, n. 5, p. 679-685, 2002.

CHIABRANDO, V.; GIACALONE, G. Effect of antibrowning agents on color and related enzymes in fresh-cut apples during cold storage, Journal of Food Processing and Preservation, Hoboken, v. 36, n. 2, p. 133-140, 2011.

CHITARRA, M.I.F.; CHITARRA, A.B. Pós-colheita de frutos e hortaliças: fisiologia e manuseio. 2.ed. Lavras: UFLA, 2005.
CIE - Comission Internationale de I'eclairage. Recommendations on uniform color spaces-color difference equations, psychomettic color terms. Paris: CIE, 1978.

DISCHE, E. Color reactions of carbohydrates. In: WHISTLER, R.L.; WOLFRAM, M.L. (Ed.). Methods in carbohydrates chemistry. New York: Academic, 1962. v.1, p.477-512.

GHIDELLI, C.; ROJAS-ARGUDO, C.; MATEOS, M.; PÉREZ-GAGO, M.B. Effect of antioxidants in controlling enzymatic browning of minimally processed persimmon 'Rojo Brillante'. Postharvest Biology and Technology, Amsterdam, v. 86, n. 1, p. 487-493, 2013.

GOMES, M.H.; FUNDO, J.F.; POÇAS, M.F.; ALMEIDA, D.P.F. Quality changes in fresh-cut 'Rocha' pear as affected by oxygen levels in modified atmosphere packaging and the $\mathrm{pH}$ of antibrowning additive. Postharvest Biology and Technology, Amsterdam, v. 74, n. 1, p. 62-70, 2012.

MACHADO, F.L.C.; ALVES, R.E.; SILVA, E.O. Processamento mínimo do melão Cantaloupe com uso de doses de cloreto de cálcio e quelato aminocálcico. Horticultura Brasileira, Vitória da Conquista, v. 28, n. 1, p. 56-60, 2008.

McCREADY, R.M.; McCOMB, E. A. Extraction and determination of total pectic materials in fruit. Analytical Chemistry, Washington, v. 24, n. 12, p. 1586-1588, 1952.

MELO, A.A.M.; VILAS BOAS, E.V.B.; JUSTO, C.F. Uso de aditivos químicos para a conservação póscolheita de banana 'maçã' minimamente processada. Ciência e Agrotecnologia, Lavras, v. 33, n. 1, p. 228-236, 2009.

OMS-OLIU, G.; ROJAS-GRAÜ, M.A.; GONZÁlEZ, L.A.; VARELA, P.; SOLIVAFORTUNY, R.; HERNANDO, M.I.H.; MUNUERA, I.P.; FISZMAN, S.; MARTÍN-BELLOSO, O. Recent approaches using chemical treatments to preserve quality of fresh-cut fruit: A review. Postharvest Biology and Technology, Amsterdam, v. 57, n. 3, p. 139-148, 2010 . 
PEREZ-CABRERA, L.; CHAFER, M.; CHIRALT, A.; GONZALEZ-MARTINEZ, C. Effectiveness of antibrowning agents applied by vacuum impregnation on minimally processed pear. LWT - Food Science and Technology, Oxford, v. 44, n.10, p. 2273-2280, 2011.

ROCHA, A.M.C.N.; MORAIS, A.M.M.B. Shelf life of minimally processed apple (cv. Jonagored) determined by color changes. Food Control, Guildford, v. 14, n. 1, p. 13-20, 2003.

SILVA, G.C.; MAIA, G.A.; FILHO, M. D.S.M.S.; FIGUEIREDO, R.W.; FILGUEIRAS, H.A.C.; SOUZA, A.C.R. Efeito de diferentes concentrações de cloreto de cálcio na qualidade do abacaxi "Pérola" minimamente processado. Revista Brasileira de Fruticultura, Jaboticabal, v. 25, n. 2, p. 216-219, 2003.
STROHECKER, R.; HENNING, H.M. Analisis de vitaminas: métodos comprobados. Madrid: Paz Montalvo, 1967. 428p.

XIAO, Z.; LUO, Y.; LUO, Y.; WANG, Q. Combined effects of sodium chlorite dip treatment and chitosan coatings on the quality of freshcut d'Anjou pears. Postharvest Biology and Technology, Wageningen, v. 62, n. 3, p. 319-326, 2011.

XISTO, A.L.R.P.; ABREU, C.M.P.; CORRÊA, A.D.C.; SANTOS, C.D. Textura de goiabas "Pedro sato" submetidas à aplicação de cloreto de cálcio. Ciência e Agrotecnologia, Lavras, v. 28, n. 1, p. 113-118, 2004. 